\title{
Medidas educativas de orientação quanto a prevenção de acidentes infantis em meio a reclusão social
}

\author{
Educational measures to guide children's accident prevention in the midst of social confinement \\ Medidas educativas para orientar la prevención de accidentes infantiles en medio del encierro \\ social
}

Recebido: 25/11/2021 | Revisado: 30/11/2021 | Aceito: 03/12/2021 | Publicado: 05/12/2021

Rhonnyckson Thayllon Silva Mendes
ORCID: https://orcid.org/0000-0001-9569-812X
Universidade Paulista, Brasil
E-mail: rhnnnys1 @ gmail.com
Vanessa da Costa Moraes
URCID: https://orcid.org/0000-0002-3242-3767
Universidade Paulista, Brasil
E-mail: vanessamoraes84619@gmail.com
Alanna Meira Carrijo Alencar
ORCID: https://orcid.org/0000-0003-1708-2199
Universidade Paulista, Brasi1
E-mail: alannacarrijo@ hotmail.com
Thaís Martins Gomes de Oliveira
ORCID: https://orcid.org/0000-0001-5227-3041
Universidade Paulista, Brasi1
E-mail: thaismmgomes @gmail.com

\begin{abstract}
Resumo
A pandemia mundial causada pela nova variante do vírus Sars-CoV-2, pertencente à família de vírus Coronaviridae, se espalhou de forma rápida mostrando um cenário alarmante para a saúde pública. Diante disso, medidas restritivas foram adotadas e uma delas foi o distanciamento social, culminando no fechamento de todos os estabelecimentos de atividades não essenciais. Objetivo: Abordar sobre a ocorrência dos acidentes domésticos voltados para o público infantil, com o intuito de instruir acerca dos seus níveis de prevenção. Método: Este é um estudo de Revisão integrativa da literatura com base numa análise descritiva, utilizando o método de análise hipotético dedutivo. Resultados: Os acidentes intradomiciliares que ocorrem por causas externas em sua maioria são 90\% evitáveis, e que podem ser evitados a partir do conhecimento dos fatores que influenciam na ocorrência deles. Tais como, idade, desenvolvimento físico, psíquico, motor influencias ambientais e sociodemográficas. É comprovado que, conforme a criança vai amadurecendo suas funções de desenvolvimento motor, se tornando, mais vulneráveis e susceptíveis a riscos. A partir disso, a orientação advinda da educação com enfoque de prevenir as ocorrências dessas situações, poderá ajudar na redução das taxas. Considerações finais: A conscientização dos responsáveis e cuidadores é um fator importante a ser levado em questão, uma vez que, a identificação prévia dos fatores de risco, é uma forma potencial de prevenção.
\end{abstract}

Palavras-chave: Acidentes domésticos; Infância; Medidas educativas; Orientação; Prevenção de acidentes; Educação em saúde; Causas externas.

\footnotetext{
Abstract

The worldwide pandemic caused by the new variant of the Sars-CoV-2 virus, belonging to the Coronaviridae virus family, has spread quickly, showing an alarming scenario for public health. Therefore, restrictive measures were adopted and one of them was social distancing, culminating in the closing of all non-essential activities establishments. Objective: Addressing the occurrence of domestic accidents aimed at children, with the aim of instructing about their levels of prevention. Method: This is an integrative literature review study based on a descriptive analysis, using the deductive hypothetical analysis method. Results: Intra-household accidents that occur due to external causes are mostly $90 \%$ preventable, and that can be avoided based on the knowledge of the factors that influence their occurrence. Such as, age, physical, psychic, motor, environmental and sociodemographic influences. It is proven that, as the child matures, their motor development functions, becoming more vulnerable and susceptible to risks. From this, the guidance provided by education with a focus on preventing the occurrence of these situations, can help to reduce rates. Final considerations: The awareness of guardians and caregivers is an important factor to be taken into account, since the prior identification of risk factors is a potential form of prevention.
} 
Keywords: Domestic accidents; Childhood; Educational measures; Guidance; Accidents prevention; Health Education; External causes.

\begin{abstract}
Resumen
La pandemia mundial provocada por la nueva variante del virus Sars-CoV-2, perteneciente a la familia del virus Coronaviridae, se ha extendido rápidamente, mostrando un escenario alarmante para la salud pública. Por tanto, se adoptaron medidas restrictivas y una de ellas fue el distanciamiento social, que culminó con el cierre de todas las actividades no esenciales. Objetivo: Atender la ocurrencia de accidentes domésticos dirigidos a niños, con el objetivo de instruir sobre sus niveles de prevención. Método: Se trata de un estudio de revisión integrativa de la literatura basado en un análisis descriptivo, utilizando el método de análisis hipotético deductivo. Resultados: Los accidentes intrafamiliares que ocurren por causas externas son en su mayoría prevenibles en un $90 \%$, y eso se puede evitar con base en el conocimiento de los factores que influyen en su ocurrencia. Tales como, influencias de edad, físicas, psíquicas, motoras, ambientales y sociodemográficas. Está comprobado que, a medida que el niño madura, su desarrollo motor funciona, haciéndose más vulnerable y susceptible a los riesgos. A partir de esto, la orientación brindada por la educación con un enfoque en prevenir la ocurrencia de estas situaciones, puede ayudar a reducir las tasas. Consideraciones finales: La conciencia de los tutores y cuidadores es un factor importante a tener en cuenta, ya que la identificación previa de los factores de riesgo es una forma potencial de prevención.

Palabras clave: Accidentes domésticos; Infancia; Medidas educativas; Guia; Prevención de accidentes; Educación para la salud; Causas externas.
\end{abstract}

\title{
1. Introdução
}

Em dezembro de 2019, em Wuhan província de Hubei, China, várias unidades de saúde notificaram a presença de casos de pacientes com sintomas semelhantes a uma pneumonia de cunho desconhecido. Assim diante do cenário epidemiológico onde mais casos incidentes de pessoas com sintomas característicos, de febre, tosse e desconforto respiratório, em 31 dezembro de 2019 as autoridades de saúde da província de Hubei, juntamente com o Centro Chinês de Controle e Prevenção de Doenças reuniram uma equipe para realizar uma análise investigatória a fim de descobrir a origem etiológica da doença (Araujo, Gubert, Tomé, Martins, Fontenele \& Barros, 2017). Após a análise, foi evidenciado uma nova variante do vírus Sars-CoV-2, pertencente à família de vírus Coronaviridae.

Diante do cenário alarmante de contágio compulsório em massa, decorrente da nova variante do vírus Sars-CoV-2, responsável por causar a doença COVID-19 que se caracteriza como um quadro clínico variado de infecções assintomáticas e sintomáticas, em 11 de março de 2020, a Organização Mundial da Saúde decretou pandemia mundial (Bezerra, Santos, Lisbinski \& Dias, 2020). Diante desta problemática, no dia 20 de março, foi publicada a Portaria de ${ }^{\circ}$ 356 do Ministério da Saúde, que estabelecia as prerrogativas a serem adotadas para o combate ao contágio do novo coronavírus. Entre elas, estavam expostas as medidas de distanciamento social (Brito, Melo, Veras, Oliveira, Bezerra \& Rocha, 2018).

Medidas estas que implicaram no fechamento e suspensão de atividades não assistenciais, dentre elas, Centros de Educação Infantil (Ceinfs) e escolas, interferindo diretamente na rotina de todos (Barcelos et al., 2018). Com isso, proporcionando o maior tempo de permanência de crianças em casa, que acaba por ocasionar situações susceptíveis à exposição de estressores e acidentes de riscos, tendo em vista que, nem sempre o lar pode oferecer melhores condições de bem-estar e segurança.

Os acidentes domésticos são situações complexas, não intencionais e podendo em $90 \%$ dos casos serem evitáveis em sua maioria por meio de medidas de prevenção. Além de serem considerados um problema de saúde pública, por provocarem custos econômicos, sociais e emocionais, gerando no ano de 2019, um gasto de R 89.288.190,48 de reais com internações por causas externas (Bressan, Gallo, Tirelli, Gregori \& Da Dalt, 2021). E de acordo com os números divulgados pelo Ministério da Saúde, em outubro de 2019 foram realizados 18.525 atendimentos, vítimas de acidentes domésticos. E em 2020, no mesmo período, o número subiu para 39.285, um aumento exponencial de $112 \%$ durante a pandemia (Da Fonseca Silva, Besborodco, Rodrigues \& Górios, 2021). 
Mediante as considerações expostas, emergiu a seguinte questão norteadora do estudo: Qual o grau de percepção por parte dos cuidadores, acerca das medidas preventivas a serem abordadas para a prevenção de acidentes domésticos voltados para o público infantil?

Os acidentes por causas externas são caracterizados pelos traumatismos, lesões ou quaisquer outros agravos à saúde, podendo eles serem categorizados como intencionais, não intencionais ou acidentais. Podendo ser provocados por eventos de transporte terrestre, quedas, envenenamentos, queimaduras, suicídio, lesões por deslizamento e outras ocorrências de causas naturais. A mortalidade por causas externas compreende diversos tipos de ocorrências, e encontram-se categorizados no capítulo XX da Décima Revisão da Classificação Internacional de Doenças e Problemas Relacionados à Saúde (CID-10). Ao todo, somente no de 2019, os acidentes por causas externas foram responsáveis por 590,1 internações por 100 mil habitantes, sendo assim, considerado um grave problema de saúde pública por gerar impactos na qualidade de vida, ocasionando na carência por hospitalização, reabilitação, mortes e gastos públicos. São considerados também, um problema de saúde pública por serem responsáveis pela maioria das internações envolvendo crianças e adolescentes.

Tendo em vista que $90 \%$ dos casos de acidentes por causas externas são evitáveis, esta pesquisa visa contribuir na conscientização dos responsáveis acerca das medidas de prevenção de acidentes e as medidas a serem tomadas após o ocorrido, por ter sido evidenciado a falta de conhecimento teórico e prático sobre as noções preventivas de acidentes domésticos e primeiros socorros (Do Espírito, 2020). Mesmo que ainda incipiente, a conscientização dos responsáveis por meio de ações preventivas e primeiros socorros, sendo embasadas por meio de conhecimentos prático-teórico junto aos profissionais de saúde, pode contribuir no preenchimento de lacunas que possibilitem no conhecimento de atividades preventivas e subsidiariamente na redução dos altos índices de acidentes infante.

Esta pesquisa visa contribuir na conscientização dos pais e responsáveis acerca dos acidentes infantis, e na identificação prévia deles, a partir de um enfoque voltado à educação em saúde, proporcionando assim, a cientificação desses saberes. Além disso, o presente estudo poderá servir como base de conhecimento e desenvolvimento para a diminuição da ocorrência de tais acidentes. E servir como base para posterior pesquisas e tecnologias que objetivam a melhoria da proteção da qualidade de vida dos menores.

Nesse ínterim, este artigo tem como objetivo, abordar sobre a ocorrência dos acidentes domésticos voltados para o público infantil em meio ao período de reclusão, com o intuito de instruir acerca dos seus níveis de prevenção

\section{Metodologia}

Este é um estudo de Revisão integrativa da literatura com base numa análise descritiva e qualitativa, utilizando o método de análise hipotético dedutivo. Após a delimitação do tema, da questão norteadora e dos objetivos a serem alcançados pela pesquisa, foram selecionados critérios de leitura, fazendo um apanhado da literatura, optando por se incluir nas pesquisas, apenas periódicos publicados nos últimos cinco anos. Para o critério de inclusão da pesquisa literária, utilizou-se os DeSC Descritores em Ciências da Saúde - da Biblioteca Virtual em Saúde, "causas externas", "acidentes", "acidentes domésticos", "infância", "primeiros socorros" "prevenção de acidentes", "educação em saúde" e para estratificação dos artigos utilizou-se o operador boleano AND.

Os artigos foram selecionados, e avaliados inicialmente pelo título e resumo. Todos aqueles que contribuíram de forma direta, ou indireta com a pergunta norteadora foram selecionados para avaliação por meio da leitura do texto na íntegra. Sendo considerado, no corpo do texto, somente aqueles que respondem a pergunta norteadora.

Para melhor norteamento da pesquisa e melhor identificação das causas externas, utilizou-se o CID-10 capítulo XX. Como critério de inclusão foram selecionadas as categorias, Quedas (W00 - W19), Afogamento e submersão acidentais (W65 - 
W74), Contato com uma fonte de calor ou com substâncias quentes (X10 - X19) e Envenenamento [intoxicação] acidental por e exposição à substâncias nocivas (X40 - X49).

Considerando as pesquisas que foram envolvidas neste trabalho, adquirimos meios de conhecimento de assuntos consideráveis, por meio de pesquisas literárias, revistas científicas, site do Ministério Saúde (MS), artigos internacionais, Sociedades Brasileiras e portarias. Por meio disso, conseguimos facilitar o esclarecimento da proposta a ser abordada no manuscrito que auxiliou no processo de esclarecimento da pesquisa.

Para aquisição do artigo, e norteamento da pesquisa, foi feita uma busca nas bases de dados eletrônicos da Scientific Electronic Library Online (Scielo), PubMed, Biblioteca Virtual da Saúde (BVS), Sociedade Brasileira de Pediatria (SBP), Revista de Enfermagem e Atenção à Saúde e Ministério da Saúde (MS).

Para a procura dos manuscritos nas bases de dados, utilizou-se os descritores "acidentes", "acidentes domiciliares", “prevenção de acidentes", "primeiros socorros" e "educação em saúde". Tendo como critério de exclusão, taxa de óbitos acometidos pelos acidentes por causas externas, prevenção de acidentes domiciliares voltados para o público gestante, neonatal, adulto e idoso.

Foram encontrados na busca primária a partir de pesquisas em bancos de dados, cinquenta artigos, dos quais destes, posteriormente, foram excluídos por serem estudos duplicados, e os estudos que depois da leitura prévia do título e resumo eram incompatíveis para o estudo e para a questão norteadora. Logo em seguida, foram selecionados dez artigos para leitura na íntegra, onde destes, dois foram excluídos pela incompatibilidade com o objetivo, e por fim quatro artigos foram incluídos nesta revisão, por se enquadrar nos requisitos e se tratar acerca dos acidentes relacionados ao público infantil e a como prevenilos. A seleção dos estudos seguiu as recomendações do método Preferred Reporting Items for Systematic Review sand MetaAnalyses- PRISMA com adaptações no fluxograma (Figura 1).

O estudo irá responder por meio de uma pesquisa da literatura atual, a percepção dos pais e educadores acerca das noções sobre acidentes domiciliares voltados para o público infantil, correspondente às idades de um a cinco anos, bem como as suas taxas de incidência e prevalência, tendo como foco a importância da orientação acerca da prevenção dos acidentes. 
Figura 1. Fluxograma prisma.

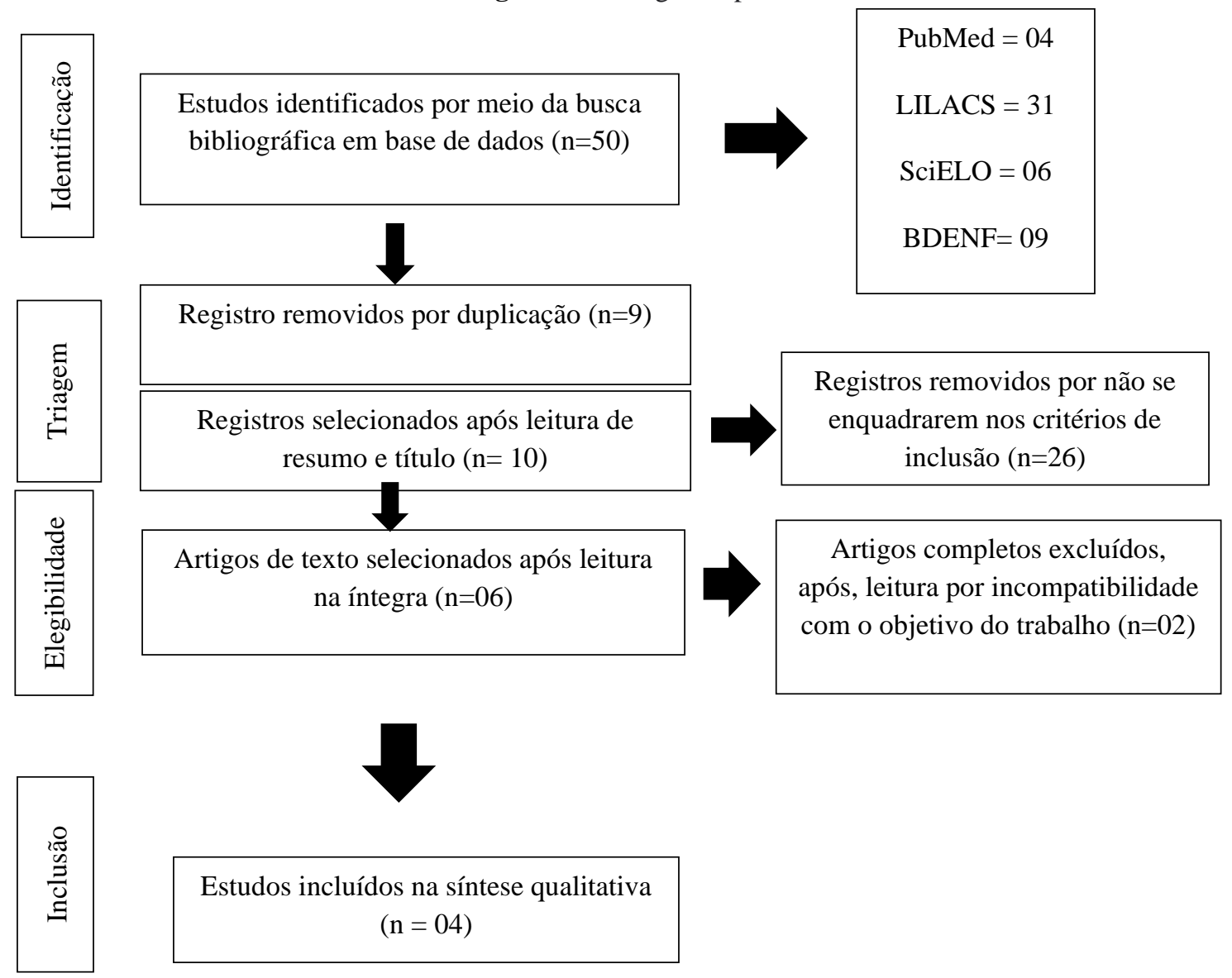

Fonte: Shamseer L, Moher D, Clarke M, Ghersi D, Liberati A, Petticrew M, et al.; PRISMA-P Group. Preferred reporting items for systematic review and meta-analysis protocols (PRISMA-P) 2015: elaboration and explanation. BMJ. 2015;350 jan02 1:g7647.

\section{Resultados}

Os quatro artigos incluídos para a realização da explanação dos resultados, foram desenvolvidos no Brasil e publicados nos últimos cinco anos. Dois estudos de caráter descritivo exploratório, um de estudo transversal e estudo exploratório, descritivo e qualitativo. Sendo que, dos quatro manuscritos incluídos nas pesquisas, dois destes foram publicados no Estado de Minas Gerais, um no Ceará-UFC e o outro no estado do Rio de Janeiro, e todos manuscritos foram desenvolvidos por mestres, professores e acadêmicos de instituições acadêmicas federais. A descrição e síntese metodológica dos principais artigos selecionados a partir da revisão integrativa estão presentes na tabela a seguir: 
Tabela 1. Descrição e síntese metodológica dos principais artigos selecionados, 07nov.

\begin{tabular}{|c|c|c|c|c|c|c|}
\hline Autoria & Objetivos & Ano & País & $\begin{array}{l}\text { Periódico / } \\
\text { área / Base } \\
\text { de Dados }\end{array}$ & $\begin{array}{l}\text { Delineam } \\
\text { ento/ } \\
\text { Nível de } \\
\text { evidência }\end{array}$ & Principais resultados \\
\hline $\begin{array}{l}\text { Helena Serpa Passos } \\
\text { Romero } 1 \text { Edna Maria } \\
\text { Rezende } 2 \text { Eunice } \\
\text { Francisca Martins } 3\end{array}$ & $\begin{array}{l}\text { Objetivou-se identificar } \\
\text { perfis de mortalidade por } \\
\text { causas externas em } \\
\text { crianças de um a nove anos } \\
\text { residentes em Minas } \\
\text { Gerais. }\end{array}$ & 2016 & Brasil & $\begin{array}{l}\text { REME rev. } \\
\text { min. enferm } \\
\text { BDENF - } \\
\text { Enfermagem / } \\
\text { LILACS }\end{array}$ & Estudo & $\begin{array}{l}\text { Foram identificados os perfis das crianças que } \\
\text { vieram a óbito, em relação as caracteriscas como } \\
\text { sexo, raça e munincipio e sua urbanização, para que } \\
\text { fossem tomadas as devidas ações de prevenção e } \\
\text { informatização. }\end{array}$ \\
\hline 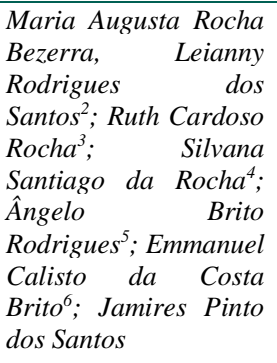 & $\begin{array}{l}\text { Objetivou-se conhecer a } \\
\text { percepção de cuidadores } \\
\text { sobre a prevenção de } \\
\text { acidentes domésticos em } \\
\text { crianças menores de cinco } \\
\text { anos. }\end{array}$ & 2016 & Brasil & $\begin{array}{l}\text { REME rev. } \\
\text { min. Enferm } \\
\text { BDENF - } \\
\text { Enfermagem / } \\
\text { LILACS }\end{array}$ & $\begin{array}{l}\text { Estudo } \\
\text { qualitativo }\end{array}$ & $\begin{array}{l}\text { As informações foram obtidas por meio de uma } \\
\text { entrevista semiestruturada abrangendo os seguintes } \\
\text { itens: características socioeconômicas e questões } \\
\text { norteadoras da pesquisa. Nas entrevistas, além de } \\
\text { serem gravadas as falas dos cuidadores, utilizando- } \\
\text { se gravador de voz, foram anotadas expressões, } \\
\text { posturas e outros elementos relativos à } \\
\text { comunicação não verbal e paraverbal, essenciais à } \\
\text { análise e compreensão do discurso dos } \\
\text { participantes da pesquisa, permitindo, assim, mais } \\
\text { fidelidade das informações. }\end{array}$ \\
\hline $\begin{array}{l}\text { Essyo Pedro } \\
\text { de Lima, Adrielle } \\
\text { Oliveira Azevedo de } \\
\text { Almeida, } \quad \text { Eveline } \\
\text { Pinheiro } \quad \text { Beserra, } \\
\text { Elioneiderraulo } \\
\text { Carneiro, Francisco } \\
\text { Mairton Rodrigues de } \\
\text { Andrade, Fabiane do } \\
\text { Amaral Gubert }\end{array}$ & 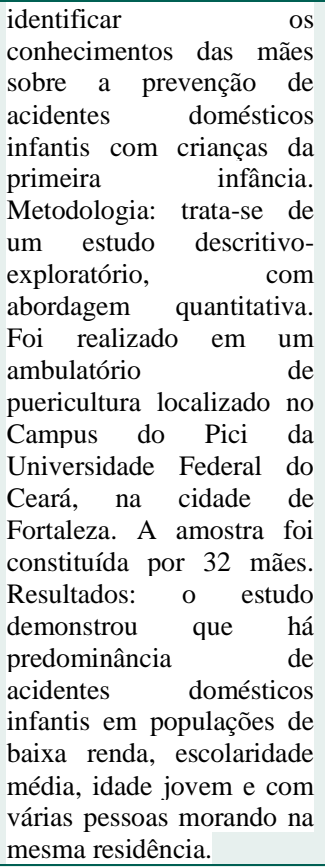 & 2018 & Brasil & \begin{tabular}{lr} 
Campus & do \\
Pici & da \\
\multicolumn{2}{l}{ Universidade } \\
Federal & do \\
Ceará, na & na \\
cidade & de \\
Fortaleza. &
\end{tabular} & $\begin{array}{l}\text { Estudo } \\
\text { descritivo- } \\
\text { exploratóri } \\
\text { o, com } \\
\text { abordagem } \\
\text { quantitativa }\end{array}$ & $\begin{array}{l}\text { Os dados são apresentados a seguir a partir dos dois } \\
\text { grupos de variáveis. Desta forma, conforme as } \\
\text { variáveis sociodemográficas e econômicas das } \\
\text { mães (tabela 1), observou-se que metade das } \\
\text { genitoras pertencem à faixa etária } 22 \text { a } 29 \text { anos. A } \\
\text { maioria mora com o companheiro }(58 \%) \text {. Das } \\
\text { entrevistadas, } 41,9 \% \text { possuem ensino médio } \\
\text { completo. Quanto à renda, } 61,2 \% \text { recebem o valor } \\
\text { mensal familiar de R } \$ 789 \text { a } 1576 \text {, o equivalente, } \\
\text { em média, de um a dois salários mínimos. Em } \\
\text { grande parte das residências moram quatro, cinco } \\
\text { ou mais pessoas, representando } 39,9 \% \text {. }\end{array}$ \\
\hline $\begin{array}{l}\text { Allyne Karlla Cunha } \\
\text { Gurgel1; Akemi Iwata } \\
\text { Monteiro2 }\end{array}$ & $\begin{array}{l}\text { descrever a percepção de } \\
\text { cuidadores domiciliares de } \\
\text { crianças quanto à } \\
\text { susceptibilidade das } \\
\text { crianças sob seus cuidados } \\
\text { para os acidentes } \\
\text { domésticos infantis. }\end{array}$ & 2016 & Brasil & $\begin{array}{l}\text { Revista de } \\
\text { Pesquisa } \\
\text { Cuidado é } \\
\text { Fundamental } \\
\text { - Online - } \\
\text { RPCF }\end{array}$ & $\begin{array}{l}\text { Estudo } \\
\text { exploratori } \\
\text { o }\end{array}$ & $\begin{array}{l}\text { todos os sujeitos julgaram os acidentes domésticos } \\
\text { infantis evitáveis. Foram identificadas percepções } \\
\text { destoantes quanto às mudanças dos riscos para } \\
\text { esses acidentes e à susceptibilidade da casa } \\
\text { habitada para esses episódios. Isso desencadeou a } \\
\text { elaboração categorias distintas, que apontavam } \\
\text { desde a existência de riscos diversos até o não } \\
\text { reconhecimento de susceptibilidade a esses } \\
\text { eventos. }\end{array}$ \\
\hline
\end{tabular}

Fonte: Autores.

O quantitativo de artigos selecionados a partir da sua revisão na íntegra, tendo em vista a rigorosidade de inclusão, explana sobre a prevalência dos acidentes infantis, ocorrerem em sua maioria, no domicílio. Tendo como predomínio dos estudos, a faixa etária de crianças com a idade entre zero a cinco anos de idade. Tendo em vista que, em todos o enfoque principal do trabalho foi com o intuito de explanar sobre a percepção dos pais e responsáveis acerca dos acidentes infantis em meio ao domicílio.

A partir da análise dos estudos incluídos nesta revisão, evidenciou-se duas vertentes a serem explanadas ao que concerne os acidentes voltados ao público infantil, fatores atenuantes e que estão diretamente relacionados. Diz respeito à 
idade da criança entrelaçada com as suas fases de desenvolvimento infantil, e a falta de orientação dos cuidadores em relação a essas fases e a identificação prévia dos acidentes.

Constatou-se que, as fases de desenvolvimento infantil desdém de uma grande influência e que a partir disso, nota-se que, conforme a criança vai evoluindo e mostrando maturidade no desenvolvimento físico, motor e psicológico, a sua vulnerabilidade e dependência por terceiros vai se tornando cada vez mais importante.

Observou-se também com a leitura na integra dos artigos selecionados, as características dos acidentes, que podem variar conforme a idade da vítima, sexo, cor ou raça e outros fatores, tais como, características sociodemográficas e econômicas.

A partir disso, foi possível delimitar uma faixa etária relacionada com os acidentes. Notou-se então que, estão mais vulneráveis e susceptíveis a ocorrência de acidentes por causas externas, crianças entre zero e quatorze anos, por passarem mais tempo em casa ficando mais expostas sendo que, a maioria destes, 59.3\% possui idade entre dois a seis meses (Filócomo, Harada, Montovani \& Ohara, 2017).

Constata-se também que, os acidentes por transportes foram os mais frequentes, corroborando os achados de outros estudos. Tal acontecimento estar mais fortemente associado às crianças na faixa etária de cinco a nove anos, e que na sua maioria foram traumatizadas como pedestres ou quando estavam dentro do próprio automóvel (Filócomo et al., 2017).

Nesse contexto, evidencia-se que o ambiente doméstico é um dos principais locais para se expressarem suas peculiaridades, e onde costuma ser o local onde as crianças passam a maior parte do tempo. Embora seja comum acreditar que a residência é o local mais seguro, é necessário desmistificar essa hipótese, uma vez que, a partir de análises, a maioria dos acidentes envolvendo os indivíduos dessa idade ocorre no domicílio (Governo Federal do Brasil, 2021).

A Partir desta análise, constata-se que, apesar do expressivo número de acidentes relacionados às crianças, 90,6\% delas não ficam totalmente desassistidas. O que se mostrou um resultado positivo, mas, que o descuido e falta de ciência acerca dos acidentes e dos seus níveis de prevenção é determinado como um possível motivo para a ocorrência de tais circunstâncias (Governo Federal do Brasil, 1987).

Conforme a leitura dos artigos, as categorias temáticas que mais se predominaram fazem alusão aos acidentes serem evitáveis, fatores socioeconômicos e sociográficos influenciarem na ocorrência dos acidentes, a nível de conhecimento para melhor evidenciação dos risco, a abordagem acerca dos níveis de prevenção deve ser comentada com os cuidadores, perceber a suscetibilidade de acordo com cada idade da criança é algo que viabilizaria a não ocorrência dessas situações, e o desenvolvimento psicomotor entrelaçado com a idade, tendo uma grande influência na ocorrência de tais circunstâncias.

Dessa forma, foi possível analisar que a ação de supervisão e o conhecimento acerca dos possíveis riscos que o ambiente intradomiciliar adjunto com a idade pode ocasionar, se torna um fator atenuante de cunho preventivo e essencial na redução dos acidentes infantis. Em suma, evidenciar os riscos se faz necessário, por ser comprovado mediante estudos científicos a grande influência que as fases de desenvolvimento junto com o ambiente de interação têm. Outra categoria elencada, diz respeito aos fatores sociodemográficos que desdém de uma grande influência. E um dos artigos que foram lidos, observou-se que o predomínio maior de ocorrência dos acidentes foi em sua maioria, em casas com infra estruturas mínimas. É notório que, a falta de ciência e de saber acerca de tal temática é um dos fatores que mais se predomina e que se torna preocupante.

\section{Discussão}

De acordo com a Portaria n 373/GM, de 16 de maio de 2001, da Política Nacional de Redução da Morbimortalidade por Acidentes e Violências, do Ministério da Saúde, define os acidentes como um o evento não intencional e evitável, causador 
de lesões físicas e ou emocionais no âmbito doméstico ou nos outros ambientes sociais, como o do trabalho, do trânsito, da escola, de esportes e do lazer (Vieira \& Souza, 2020).

Os acidentes ou traumas não intencionais, correspondem a situações em que a pessoa acaba sofrendo algum tipo de dano físico, ou psíquico, sendo ocasionado por um trauma, independente de ação direta ou não. Como é o caso dos acidentes domésticos voltados ao público infantil, que são considerados um grande problema de saúde pública, tendo em vista os gastos e custos gerados por ano. Traumas estes que poderiam ser evitados em sua maioria com medidas simples de prevenção e proteção, evitando as possíveis sequelas que eles podem ocasionar (Filócomo et al., 2017).

Muitos estudos fazem alusão ao desenvolvimento psicomotor entrelaçado à idade da criança, mas, que, características sociodemográficas juntamente com condições econômicas, moradia e questões culturais estão intrinsecamente relacionados aos acidentes voltados para esta faixa etária. Sendo que, os acidentes e violências revelam uma predominância de mortes, e os acidentes por causas externas o primeiro motivo de morte infantil no país.

A primeira infância, etapa que se inicia nos primeiros anos de vida, particularmente, os três primeiros anos de vida, é marcada por ser uma fase determinante para o desenvolvimento cognitivo, emocional e social da criança. Destaca-se que, é nessa fase que as crianças são mais vulneráveis a situações de acidentes, tendo em vista que, a mesma estar passando por uma fase de maturação e que muitas vezes a percepção do que é certo ou errado, e do que é perigoso ainda é distorcida e incompreensível. Mas, entende-se que, quanto menor a idade, maiores são os riscos e a suscetibilidade para a ocorrência dos acontecimentos externos. O Que pode afetar diretamente o crescimento e o desenvolvimento. Fazendo com que, a dependência por terceiros seja mais que essencial (Vieira et al., 2020).

Tal compreensão, é importante quando associada à imaturidade cognitiva e motora das crianças, o que consequentemente promove sua incapacidade de se defender sozinha, dependendo, portanto, de outros para que sua segurança seja garantida.

Ao que se refere o desenvolvimento psicomotor, observa-se uma fase permeada por intensa energia e curiosidade, e por meio disto a aquisição de conhecimento e habilidades, e assim, uma maior exposição aos riscos. Tornando necessário um ambiente minimamente seguro (Filócomo et al., 2017).

Os acidentes que mais se destacam na literatura são as quedas, queimaduras, sufocamento, afogamentos, intoxicações e corte. O que ocorre na maioria dos domicílios, independentemente do nível social intelectual dos indivíduos, e que nem sempre significa um ato de negligência por parte dos cuidados, que pode ocasionar em hospitalizações acompanhadas de sequelas agravantes ou não, e até na morte da criança (Jorge, 2021).

Observou-se também durante a pesquisa, os achados referentes às diferenças comportamentais de cada sexo, o que tem a ver com determinantes culturais. Uma vez que, culturalmente e socialmente, aos meninos é dada mais liberdade, em contrapartida que há mais vigilância às meninas. Isso pode ser justificado a partir da coleta de dados que mostram uma taxa maior de morte por causas externas para o público masculino (Governo Federal do Brasil, 2021).

Percebe-se que, de acordo com a literatura, no espaço doméstico as crianças estão passíveis a uma grande variedade de riscos e isso pode ser justificado a partir do seu reduzido desenvolvimento físico e psicológico, advindo, pela dificuldade de seus cuidadores em perceber tais riscos e trabalhar em cima deles com o intuito de diminuir a ocorrências dos acidentes. O Que traz a necessidade de serem abordados mais frequentemente, visto que, a ocorrência deles pode culminar em internações, sequelas sérias e nos casos mais graves e irreversíveis a morte (Governo Federal do Brasil, 1987).

Para que a prevenção seja eficaz, é necessário que se tenha o conhecimento sobre as fases de crescimento e desenvolvimento da criança, e que, mesmo quando a criança não adquire habilidades de se locomover, outras habilidades já desenvolvidas podem ser aplicadas na ocorrência de acidentes. 
É importante debater que os acidentes domiciliares envolvendo crianças têm causas e consequências complexas. E que para a sua prevenção, é necessário a compreensão de múltiplos fatores que influenciam diretamente na ocorrência deles. Entende-se que, não é só a criança que acaba sofrendo, pois envolve em parte o cuidador, a família, o ambiente e todos envolvidos no cenário. Sabe-se que, a supervisão é uma forma adequada de prevenção e uma parte significativa na redução dos riscos, mas mesmo assim, é inegável que trabalhar em cima de ferramentas que possibilitem a identificação prévia dos riscos entrelaçados com a idade, é um fator atenuante para a redução dos acontecimentos, podendo tornar todo e qualquer acidente previsto e evitável (Governo Federal do Brasil, 2021).

Levando em consideração ao exposto, as crianças estão mais susceptíveis a sofrer esses riscos, em decorrência da sua idade e maturidade. Quanto menor a idade, menor será a compreensão de riscos e maior a sua suscetibilidade e vulnerabilidade, tendo em vista a dependência de outras pessoas. No caso os responsáveis devem se atentar aos possíveis riscos que podem ser evidenciados no domicílio (Margotti \& Corrêa, 2018).

Segundo a Sociedade Brasileira de Pediatria, os acidentes domésticos são a principal causa de morte de crianças com idade de um a quatro anos no Brasil. De acordo com os dados publicados em 2018 pela Organização das Nações Unidas para a Infância (UNICEF), a taxa de mortalidade no Brasil é de vinte e sete óbitos para cada mil, enquanto em outros países desenvolvidos, essa taxa é de apenas três óbitos. São feitas cerca de cento e onze mil hospitalizações devido a causas externas no país, e mais da metade ocasionadas por quedas e queimaduras (Margotti et al., 2018).

A residência e o seu entorno, devem se tornar locais seguros, e preparados para as possibilidades de exploração e de suas tentativas e erros, e além disso, que seja capaz de enfrentar os desafios que cada idade propõe e os seus riscos. Sendo necessário, ter a conscientização da necessidade de proteção bem como as etapas de desenvolvimento de cada idade para que por meio disso, possa se haver a prevenção de acidentes, minimizando a incidência dos traumas.

A maioria dos acidentes não intencionais que acontecem nos domicílios estão ligados a queimaduras, quedas, envenenamento e intoxicação, que podem acarretar danos físicos temporários, permanentes e/ou em casos mais graves a morte. Esses acontecimentos são resultantes de interações genéticas, fatores comportamentais, ambiente e características dos pais (Marcheti, Luizari, Marques, Cañedo, Menezes \& Volpe, 2020).

Deve-se levar em conta, as características relacionadas à vulnerabilidade, o nível de coordenação do sistema nervoso, aptidão motora, senso de percepção de risco, desenvolvimento cognitivo, motor, físico e a dependência por parte dos seus cuidadores (Jorge, 2021).

As medidas de bloqueio prolongadas, em decorrência da covid-19, puderam ajudar na potencialização dos números voltados a acidentes domiciliares (Malta, Mascarenhas, Silva, Carvalho, Barufaldi, Avanci \& Bernal, 2016). Ressalta-se que cada espaço tem o seu potencial de risco, devendo ele ser reconhecido, como é o caso das tomadas de luz que podem resultar em choques e queimaduras, janelas que provoca possíveis quedas, lavanderia, baldes, bacias que ocasiona acúmulo de água, culminando em possíveis afogamentos e produtos de químicos de limpeza, possíveis maneira de intoxicação. Lembrando que, a cozinha é considerada o local onde ocorre a maioria das queimaduras.

As quedas são os acidentes por causas externas de maiores prevalências na infância, de acordo com a literatura (Silva, Mekaro, Santos \& Uehara, 2020). Segundo dados do Ministério da Saúde, em 2019, cinquenta e duas mil seiscentas e treze crianças foram hospitalizadas, com idades de zero a quatro anos. Já as internações por queimaduras, no ano de 2019, mostraram um expressivo resultado, de vinte e uma mil e três crianças hospitalizadas, resultando na morte de duzentas crianças por esse motivo, sendo que destes, noventa e seis tinham de um a quatro anos de idade. Quanto às internações por intoxicação, por produtos químicos de limpeza, remédios e álcool em gel, subiu 11\% no último ano (De Fátima Magalhães, De Toledo Nobre, Theis \& Basegio, 2021), correspondendo no de 2019, à faixa de três mil e oitocentas hospitalizações. E a sufocação, estando mais vulneráveis as crianças menores de 4 anos, que segundo o Ministério da Saúde, em 2018, setenta e nove crianças 
de até quatorze anos morreram vítimas de sufocação, onde desse total, seiscentas eram menores de um ano (Malta, Mascarenhas et al., 2016).

Constata-se também que, no domicilio á o acesso mais fácil a substâncias que podem ser nocivas e causas potenciais danos a esse público, como os medicamentos $(79,8 \%)$ e materiais de limpeza $(86,1 \%)$ (Silva et al., 2020).

A residência é vista como o principal local para a ocorrência desses acidentes, sendo que $30 \%$ deles acontecem nos domicílios (Neto, Moro, De Freitas \& Mandetta, 2020). Diante do atual cenário, de enfrentamento a pandemia, pode-se afirmar que é compreensível que as crianças estejam mais susceptíveis a tais acidentes, bem com os acidentes de consumos, que de acordo com o conceito praticado pelo Inmetro (2020) 'ocorrem quando um produto ou serviço provoca danos à saúde ou à segurança do consumidor, mesmo quando utilizado adequadamente ou de acordo com as instruções de uso indicadas pelo fornecedor',(pág. 1) No ano de 2019, segundo dados do Sistema Inmetro de Monitoramento de Acidentes de Consumo (Sinmac) cerca de $24 \%$ dos acidentes relatados afetaram crianças, $31 \%$ deles ocasionados por produtos de uso infantil. Sendo $54 \%$ ocasionados por carrinho de bebê, $31 \%$ escadas, $8 \%$ Fonte de alimentação para computadores e $7 \%$ brinquedos (Portal da Defesa do Consumidor, 2021).

Com isso, os acidentes repercutem não só na saúde física e psíquica das crianças, mas também no seu bem-estar e das famílias. Causando grandes custos econômicos com internações, assistência e dependendo da gravidade, acompanhamento médico por toda a vida. Assim, os acidentes domésticos são caracterizados como uma das principais causas de assistência, internação, incapacidade e mortes na infância. Tendo uma grande contribuição no aumento exponencial das altas taxas de morbidade e mortalidade infantil.

Segundo dados do Sistema de Informações sobre mortalidade, em 2017 três mil cento e noventa e sete crianças de zero a nove anos morreram vítimas de acidentes por causas externas, sendo cento e quarenta destes corresponderam a quedas, mil quatrocentos e duas por sufocação, afogamento e obstrução de vias aéreas (Oliveira, Duarte, França \& Garcia, 2021). Os números relacionados a prevalência e incidência de acidentes domésticos, ocasionados por causas externas não são desprezíveis, pois eles nos mostram a real complexidade do problema.

De acordo com o presidente do Departamento de Segurança da Sociedade Brasileira de Pediatria (SBP), Marco Antônio Chaves Gama, explica que crianças menores de quatro anos têm uma chance maior de se machucar, devido a sua curiosidade e falta de percepção acerca dos riscos (Bezerra, Rocha, dos Santos Negreiros, de Morais Lira, de Souza \& Santiago, 2014). Os fatores de riscos para a ocorrências de acidentes não devem se resultar apenas a idade e sexo, mas serem considerados multifatoriais. Devendo ser levado em consideração outros aspectos, tais como moradia, espaço, membros da família, o tempo de ausência dos seus cuidados, deixando essa população desassistida, que influenciam na expressa alta dos números de acidentes por causas externas (Portal da Defesa do Consumidor, 2021).

Como foi supracitado, o conhecimento e percepção por parte dos pais e cuidadores responsáveis, acerca dos riscos presentes no seu domicílio, por mais que este local seja visto como um ambiente que dispõe de uma infraestrutura minimamente segura, é algo imprescindível que não deve ser destacado. Bem como, as características comportamentais, físicas e psíquicas que cada idade apresenta. Trabalhar nessa perspectiva resultaria significativamente na redução das taxas de morbimortalidade desse público.

Vale salientar que, os acidentes domésticos com crianças de zero a cinco anos são frequentes, uma vez que é nessa idade, que observamos o surgimento de algumas características no seu desenvolvimento que vai passando por mudanças comportamentais conforme a idade. Assim as crianças se tornam independentes para andar, ademais temos uma melhora na motricidade fina em decorrência da prática, aumento da coordenação e equilíbrio, dispõe de grande habilidade motora, compreende a maior parte do que ouve, aumenta a sua curiosidade e necessidade de exploração do meio no qual está inserida (Sociedade Brasileira de Queimados, 2021). 
Diante da magnitude do problema, o enfermeiro em sua autonomia, possui um papel fundamental na sua atuação no que concerne ao cuidado, prevenção, promoção e recuperação da saúde, por ser um profissional capacitado no âmbito da educação técnica e humanista, sendo respaldado pelo decreto n 94.406/87 do Conselho Federal de Enfermagem, onde no seu Art. 8, Inciso $\mathrm{I}^{25}$ dispõe sobre o exercício da enfermagem, expondo as funções privativas do enfermeiro, como a participação no planejamento, execução e avaliação dos planos assistenciais de saúde (Bezerra et al., 2020).

Este profissional, detém de um papel mais que essencial, uma vez que na sua prática ele trabalha desenvolvendo ações de promoção da saúde, que são um conjunto de estratégias e formas de produzir saúde. Desta forma o enfermeiro deve atuar como um dos principais profissionais responsáveis pela realização de atividades em saúde, se colocando em uma posição de educador, por possuir um vínculo maior com a família, contribuído diretamente na mudança do estilo de vida e na melhoria da qualidade de vida, minimizando os fatores de riscos e promovendo o protagonismo em saúde (Silva et al., 2020).

As consequências resultantes deste cenário, causam grandes danos e impactos na economia e saúde para a sociedade. Com isso, é mais que imprescindível a ampliação das ações de conscientização, por parte dos pais e cuidadores responsáveis, juntamente com a sociedade. Sendo importante ressaltar que os acidentes, em 90\% deles, são evitáveis.

A falta de políticas públicas serve como um indicador importante, comprovando que a ausência destas, ajudam a aumentar as estatísticas (Malta et al., 2016).

Os acidentes representam um grande problema de saúde pública, causando prejuízos muitas das vezes irreversíveis, acarretando em sequelas graves e permanentes (Jorge, 2021).

Outro problema a ser questionado, diz respeito à existência de políticas públicas desconhecidas, pouco pautadas e colocadas em prática. Como é o caso da política Nacional de Redução da Morbimortalidade por Acidentes e Violências, criada em 2001 pelo Ministério da Saúde, com o intuito de reduzir a morbimortalidade por acidentes e violência e em 2006 o Sistema de Vigilância e Acidentes que utiliza inquéritos periódicos de serviços em urgência e emergência da rede assistencial do Sistema Único de Saúde (SUS) (Vieira et al., 2020).

Dessa forma, o profissional de enfermagem detém de um papel importante na orientação quanto à prevenção desses acidentes, contribuindo de forma notória na disseminação e propagação da educação em saúde (Neto et al., 2020).

Os profissionais devem desenvolver programas de prevenção com a realização de palestras de conscientização acerca dos riscos, com o intuito de reduzir as taxas de morbimortalidade ocasionadas por estes acidentes. É imprescindível a identificação dos riscos de saúde no ambiente.

A ocorrência desses acidentes pode estar relacionada a múltiplos fatores, estando intimamente relacionados ao comportamento familiar, aspectos sociais, econômicos, educacionais e culturais. Medidas preventivas eficazes incluem uma gama de iniciativas, sendo de suma importância a ampliação da ação, para além da saúde, apostando em ações que devem ser desenvolvidas em conjunto com a sociedade. Tais iniciativas, contribui no pensamento crítico-reflexivo, sobre a necessidade de adotar comportamentos preventivos a fim de minimizar os acidentes domésticos voltados a esse público.

\section{Conclusão}

Há evidências na literatura que os acidentes por causas externas compreendem um número expressivo e os mesmo, revelam um grave problema de saúde por acarretarem em internações com longos períodos de permanência, prejuízos emocionais e também, acarretar em situações complexas a criança. A partir disso, compreende-se a importância do enfoque preventivo ao que concerne aos acidentes voltados à este público.

Tendo em vista que, grande parte das pesquisas elucidaram sobre o fato de $90 \%$ dos acidentes serem preventivos, e que o público mais suscetível e vulnerável são as crianças, em suma, diante do atual cenário pandêmico, a permanência desse 
público mais tempo em suas residências se tornou um fator atenuante para o aumento dos índices e taxas dos acidentes domiciliares.

A conscientização dos pais e responsáveis é um fator importante a ser levado em questão, uma vez que, a identificação prévia dos fatores de risco, é uma forma potencial de prevenção. Adentrando à isso, a participação direta dos profissionais de enfermagem na promoção desses saberes é essencial, para que a conscientização seja mais eficaz e resolutiva, algumas formas as quais podem ser realizadas essa conscientização são, por meio de palestras educativas, cursos especializados, cartilhas e documentos físicos ou digitais distribuídos por meio de redes sociais.

No mais, por meio deste estudo tivemos a reflexão da importância de políticas públicas de conscientização desses acidentes, e além disso, o quão notório se faz a presença dos profissionais de saúde, especificamente o enfermeiro que ativamente atua nas alas de urgência e emergência em suporte básico e avançado de vida, assistência a IAM e AVE, atendimento a vítimas de traumas que estão estritamente correlacionadas com os primeiros socorros, e diante da propagação desses saberes. Uma vez que, como lhe é respaldado, na sua atuação profissional, ações de prevenção e promoção são essenciais para a redução dos números alarmantes.

\section{Referências}

Araújo, A. R., Gubert, F. D. A., Tomé, M. A. B. G., Martins, M. C., Fontenele, N. L., \& Barros, E. C. (2017). Prevenção de acidentes em uma creche: experiência com pais, professores e pré-escolares. Revista de Enfermagem UFPE OnLine.[Internet], 11(Supl 4), 1671-8. https://periodicos.ufpe.br/revistas/revistaenfermagem/article/viewFile/15264/18063

Barcelos, R. S., Santos, I. S., Matijasevich, A., Barros, A. J., Barros, F. C., França, G. V. A., \& Silva, V. L. S. D. (2017). Acidentes por quedas, cortes e queimaduras em crianças de 0-4 anos: coorte de nascimentos de Pelotas, Rio Grande do Sul, Brasil, 2004. Cadernos de Saúde Pública, 33. https://www.scielo.br/j/csp/a/K8RHVbY7pRWd4xMpRk665zG/?lang=pt

Barcelos, R. S., Del-Ponte, B., \& Santos, I. S. (2018). Intervenções para redução de acidentes na infância: revisão sistemática`̧. Jornal de Pediatria, 94, 351367. https://www.scielo.br/j/jped/a/cqtqX4VsnYZn96wVQQ6pVXB/?lang=pt\&format=html

Bezerra, É. C. D., Santos, P. S. D., Lisbinski, F. C., \& Dias, L. C. (2020). Análise espacial das condições de enfrentamento à COVID-19: uma proposta de Índice da Infraestrutura da Saúde do Brasil. Ciência \& Saúde Coletiva, $25, \quad 4957-4967$. https://www.scielo.br/j/csc/a/XP3Q7jyggBkT95BswnKQYwy/abstract/?lang=pt

Bezerra, M. A. R., Rocha, R. C., dos Santos Negreiros, F., de Morais Lira, F. M. O., de Sousa, L. T., \& Santiago, S. C. G. (2014). Acidentes domésticos em crianças: concepções práticas dos agentes comunitários de saúde. Cogitare Enfermagem, 19(4). https://scholar.googleusercontent.com/scholar ?q=cache:IBdXAWa91N4J:scholar.google.com/+ACIDENTES+DOM\%C3\%89STICOS+EM+CRIAN\%C3\%87AS:++++CONCEP\%C3\%87\%C3\%95ES+PR \%C3\%81TICAS+DOS+AGENTES+COMUNIT\%C3\%81RIOS+DE+SA\%C3\%9ADE.\&hl=pt-BR\&lr=lang_pt\&as_sdt=0,5

Bressan, S., Gallo, E., Tirelli, F., Gregori, D., \& Da Dalt, L. (2021). Lockdown: more domestic accidents than COVID-19 in children. Archives of disease in childhood, 106(2), e3-e3. https://adc.bmj.com/content/106/2/e3.abstract

Brito, M. D. A., Melo, A. M. N., Veras, I. D. C., Oliveira, C. M. S. D., Bezerra, M. A. R., \& Rocha, S. S. D. (2018). Fatores de risco no ambiente doméstico para quedas em crianças menores de cinco anos. Revista Gaúcha de Enfermagem, 38. https://www.scielo.br/j/rgenf/a/6WXnfF y7LDNdDQns6BbCRHC/abstract/?lang=pt

da Fonseca Silva, C. V., Besborodco, R. M., Rodrigues, C. L., \& Górios, C. Isolamento social devido a COVID-19-Epidemiologia dos acidentes na Infância e Adolescência. https://cdn.publisher.gn1.link/residenciapediatrica.com.br/pdf/pprint402.pdf

de Fátima Magalhães, D., de Toledo Nobre, K. F., Theis, L. C., \& Basegio, L. F. (2021). Acidentes na primeira infância: contribuições da Enfermagem na construção de orientações preventivas. Research, Society and Development, 10(2), e21010212415-e21010212415. https://rsdjournal.org/index.php/rsd/article/view/12415

do Espírito, C. D. B. M. (2020). Prevenção aos acidentes domésticos e guia rápido de primeiros socorros. https://www.gov.br/mdh/ptbr/assuntos/noticias/2020-2/abril/ministerio-publica-guia-de-prevencao-a-acidentes-domesticos-e-primeiros

Filócomo, F. R. F., Harada, M. D. J. C. S., Mantovani, R., \& Ohara, C. V. D. S. (2017). Perfil dos acidentes na infância e adolescência atendidos em um hospital público. Acta Paulista de Enfermagem, 30, 287-294. https://www.scielo.br/j/ape/a/6PVvWPHVthy3SfF6ySM7DVc/?lang=pt

Governo Federal do Brasil. Acidentes com crianças: o que você pode fazer para mudar essa estatística? https://www.gov.br/inmetro/pt-br/centrais-deconteudo/noticias/acidentes-com-criancas-o-que-voce-pode-fazer-para-mudar-essa-estatistica\#: :text=Instale $\% 20 \mathrm{e} \% 20 \mathrm{fa} \% \mathrm{C} 3 \% \mathrm{~A} 7 \mathrm{a} \% 20 \mathrm{inspe} \% \mathrm{C} 3 \% \mathrm{~A} 7 \% \mathrm{C} 3$ $\%$ B5es\%20peri\%C3\%B3dicas,ter\%20o\%20 selo\%20do\%20Inmetro.

Governo Federal do Brasil. Decreto No 94.406. 08 jun 1987. http://www.planalto.gov.br/ccivil_03/decreto/1980-1989/d94406.htm 
Research, Society and Development, v. 10, n. 16, e327101623913, 2021

(CC BY 4.0) | ISSN 2525-3409 | DOI: http://dx.doi.org/10.33448/rsd-v10i16.23913

Jorge, O. M. B. Prevenção de acidentes domésticos no Distrito Federal. https://www.arca.fiocruz.br/handle/icict/36920\#: :text=OP\%C3\%87 \%C3\%95ES\%20PA RA\%20ENFRENTAR\%20O\%20PROBLEMA,Op\%C3\%A7\%C3\%A3o\%204\%20\%2D\%20Orienta\%C3\%A7\%C3 \%A3o\%20e\%20e duca $\% \mathrm{C} 3 \% \mathrm{~A} 7 \% \mathrm{C} 3 \% \mathrm{~A} 3 \mathrm{o}$

Malta, D. C., Mascarenhas, M. D. M., Silva, M. M. A. D., Carvalho, M. G. O. D., Barufaldi, L. A., Avanci, J. Q., \& Bernal, R. T. I. (2016). A ocorrência de causas externas na infância em serviços de urgência: aspectos epidemiológicos, Brasil, 2014. Ciência \& Saúde Coletiva, 21, 3729-3744. https://www.scielosp.org/article/csc/2016.v21n12/3729-3744/pt/

Marcheti, M. A., Luizari, M. R. F., Marques, F. R. B., Cañedo, M. C., Menezes, L. F., \& Volpe, I. G. (2020). Acidentes na infância em tempo de pandemia pela COVID-19. Rev. Soc. Bras. Enferm. Ped, 20(spe), 16-25. https://journal.sobep.org.br/wp-content/uploads/articles_xml/2238-202X-sobep-20-spe0016/2238-202X-sobep-20-spe-0016.x65337.pdf

Marco, A. C. G., Luci, Y. P., Adriana, R. B., Ana, L. F., Renata, D. W., Sarah, S., et Al. Os acidentes são evitáveis e na maioria das vezes, o perigo está dentro de casa! https://www.sbp.com.br/imprensa/detalhe/nid/os-acidentes-sao-evitaveis-e-na-maioria-das-vezes-o-perigo-esta-dentro-de-casa/

Margotti, E., da Costa, P. P. S., \& Corrêa, A. M. C. (2018). A importância da prevenção de acidentes na infância: um relato de experiência. Revista de Enfermagem e Atenção à Saúde, 7(1). http://seer.uftm.edu.br/revistaeletronica/index.php/enfer/article/view/2281

Neto, W. S. B., Moro, S., De Freitas, T. G., Mandetta, L. H., others. Portaria no 133, de 23 de março de 2020. https://www.in.gov.br/en/web/dou/-/portaria-n133-de-23-de-marco-de-2020-249317436

Oliveira, W. K., Duarte, E., França, G. V., Garcia, L. P. Como o Brasil pode deter a COVID-19. Epidemiologia e Serviços de Saúde. https://www.scielosp.org/pdf/ress/2020.v29n2/e2020044/

Portal de Defesa do Consumidor. (2016) Sistema que monitora acidentes de consumo. Brasil https://www.defesadoconsumidor.gov.br/portal/ultimasnoticias/89-sistema-que-monitora-acidentes-de-consumo-esta-disponivel-no-portal-de-defesa-do-consumidor

Santos, M. E. A., Quintão, N. T., \& Almeida, R. X. D. (2010). Avaliação dos marcos do desenvolvimento infantil segundo a estratégia da atenção integrada às doenças prevalentes na infância. Escola Anna Nery, 14, 591-598. https://www.scielo.br/j/ean/a/3fGzpWQGjnRHPp7HQXH5fDJ/?format=pdf\&lang=pt

Silva, N. C. D. C. D., Mekaro, K. S., Santos, R. I. D. O., \& Uehara, S. C. D. S. A. (2020). Conhecimento e prática de promoção da saúde de enfermeiros da Estratégia Saúde da Família. Revista Brasileira de Enfermagem, 73(5). https://www.scielo.br/j/reben/a/zHjjstjKpqMbr4SDYt3g83G/?lang=pt

Sociedade Brasileira de Queimados. (2020) Prevenção de acidentes domésticos com crianças e adolescentes. https://www.sejus.df.gov.br/sejus-lanca-cartilhade-prevencao-a-acidentes-domesticos-com-criancas-e-adolescentes/

Sociedade Brasileira de Pediatria. Papel do pediatra na prevenção após acidentes com crianças e adolescentes. https://www.sbp.com.br/imprensa/detalhe/nid/papel-do-pediatra-na-prevencao-apos-acidentes-com-criancas-e-adolescentes-foi-abordado-no-38o-cbp/

Vieira, E. C. G., \& Souza, G. M. P. D. (2020). Prevalência de acidentes domésticos infantis no Brasil. https://dspace.uniceplac.edu.br/handle/123456789/279 